\title{
Neural Network Compensation Control for Output Power Optimization of Wind Energy Conversion System Based on Data-Driven Control
}

\author{
T. Li, ${ }^{1}$ A. J. Feng, ${ }^{1}$ and L. Zhao ${ }^{2}$ \\ ${ }^{1}$ Key Laboratory of Advanced Process Control for Light Industry of Ministry of Education, Jiangnan University, Wuxi 214122, China \\ ${ }^{2}$ Department of Mechanical and Electrical Engineering, Shan Dong Water Polytechnic, Rizhao 276826, China
}

Correspondence should be addressed to T. Li, mybesttl@126.com

Received 29 March 2012; Revised 8 May 2012; Accepted 17 May 2012

Academic Editor: Wen Yu

Copyright (C) $2012 \mathrm{~T}$. Li et al. This is an open access article distributed under the Creative Commons Attribution License, which permits unrestricted use, distribution, and reproduction in any medium, provided the original work is properly cited.

\begin{abstract}
Due to the uncertainty of wind and because wind energy conversion systems (WECSs) have strong nonlinear characteristics, accurate model of the WECS is difficult to be built. To solve this problem, data-driven control technology is selected and datadriven controller for the WECS is designed based on the Markov model. The neural networks are designed to optimize the output of the system based on the data-driven control system model. In order to improve the efficiency of the neural network training, three different learning rules are compared. Analysis results and SCADA data of the wind farm are compared, and it is shown that the method effectively reduces fluctuations of the generator speed, the safety of the wind turbines can be enhanced, the accuracy of the WECS output is improved, and more wind energy is captured.
\end{abstract}

\section{Introduction}

In recent years, the global wind industry has grown rapidly, wind energy has become one of the most important renewable energy sources, installed capacity growth rate of wind turbines has become more than $25 \%$ annually, and wind energy has been widely applied to water irrigation [1], urban power supply [2], and many other fields. However, there are still some difficult issues in wind energy control technology: how to get maximum power output of wind turbine is one of the main concerns. Domestic and foreign scholars have done a lot of research on capturing the largest wind energy; the most common control strategy is maximum power point tracking control (MPPT) [3]. The maximum wind energy is captured by controlling the output error of the wind generator speed, when the wind speed changes. PI control $[4,5]$, LQG control $[6,7]$, and Fuzzy sliding mode control [8] are commonly used as the control methods. However, the parameters of PI controller are almost adjusted through a large number of experiments. They will be affected by the change of load and wind speed, and therefore, PI regulator will lose the flexibility at this time. The LQG control method does not have high modeling accuracy, so the error of system output is too large. Fuzzy sliding mode control cannot reduce the chattering phenomenon; it will lead to low accuracy and poor robust performance.

Data-driven control theory has gradually become a hot research area for domestic and foreign scholars [9-14]. The data-driven control theory can be used to design a controller for a complex nonlinear system whose model is unknown. The control method has general applicability and is successfully applied to many fields, such as flight control $[15,16]$, pattern recognition [17], and robot control $[18,19]$.

However, the shortcomings of the data-driven controller are parameter perturbation and excessive computing. The data-driven approach is improved by many well-known scholars [20-23]. A new data-driven controller is designed in the literature [20]; the method uses only measured input and output data of the controlled plant and guarantees bounded input and bounded output stability. It can be known by comparing this data-driven approach with the general adaptive control approach. The method has practical 


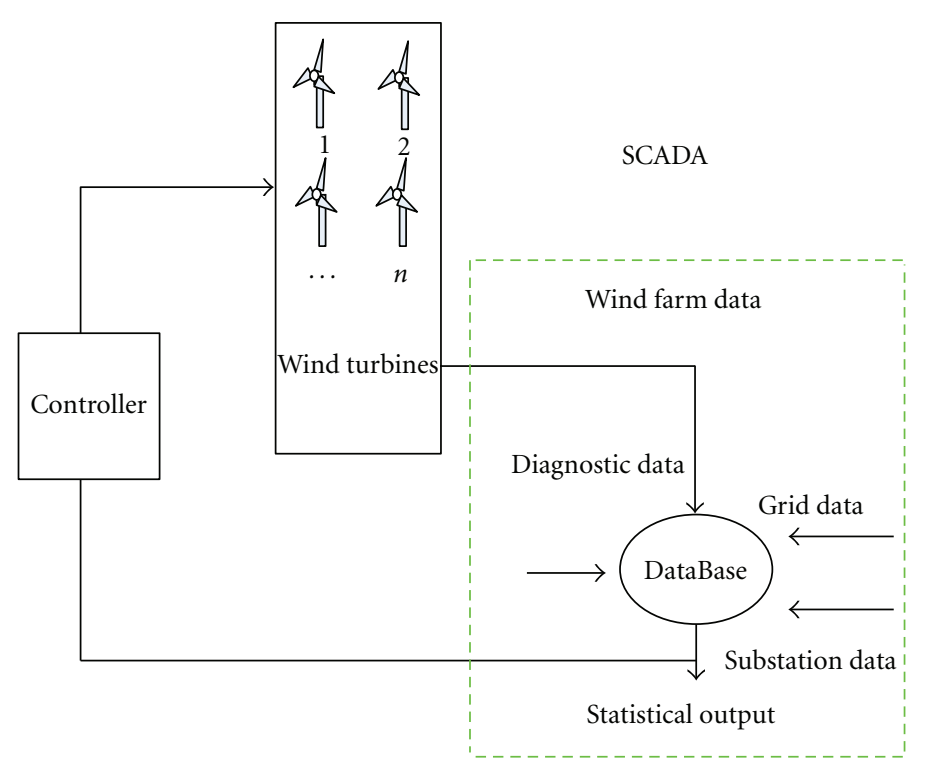

Figure 1: SCADA system for wind farm.

application value and can be combined with other control methods, and thus the cost of the controller is greatly reduced.

Neural networks have independence-not relying on accurate mathematical model of the system-and a strong classification ability for spatial data model. In fact, neural networks have been successfully applicated to wind power control systems [24-30]. Literatures [24-26] introduce the neural network predictive control in the application of the WECS, using neural network predictive controller to compensate system output errors that are caused by uncertainty parameters in WECS; disturbance output is reduced when the wind turbine is at run time. Literatures $[31,32]$ introduce observers applied to wind turbines; robust performance and dynamic performance of the WECS can be improved by the observers. When wind speed is larger, power output may exceed the rated value; this will cause high wind turbine torque load. Power output quality of the WECS is optimized by controlling the blade pitch angle in literatures [27, 28], so the wind turbine shutdown and overload can be reduced. There exist analytical models of wind turbines as in [33-36] and models based on input output data as in [29, 30,37], and in the paper, the second case is considered. Literatures $[29,30,37]$ introduce data-driven controller designed for the WECS based on neural network, this method collects wind farms data by supervisory control and data acquisition (SCADA) system, such as wind energy utilization coefficient, wind generator speed, and wind speed. Using data-driven control to identify input and output of the controlled object, different control methods are used to regulate WECS output; the results proved that this method can be effectively applied to different wind turbines.

Data-driven controller for the WECS based on neural network compensation control is designed in this paper. Firstly, a 10 min data of wind turbine was selected by SCADA system; the data-driven control system Markov parameters can be obtained by input and output data of the WECS. Secondly, the controller gain can be obtained by closed solution of differential Riccati.

In order to improve the WECS control precision and capture more wind energy, a neural network compensator is designed to counteract dynamic disturbances caused by unkown parameters of the WECS, different neural network learning rules are selected in the training process, and another neural network is used to optimize the wind energy utilization coefficient and reduce the mechanical shocks on the WECS. Analysis results show that this way more wind energy can be captured and safety of the wind turbine can be enhanced.

\section{Problem Description}

Wind speed and wind direction are uncontrollable variables while, wind generator speed and torque are controllable variables $[29,30,37,38]$. The SCADA system of wind turbines is shown in Figure 1; the system can monitor multiple wind farm data, for example, wind turbines, grid data, and substation data. Data of output power, wind generator speed, wind generator torque, and wind speed is selected in this paper.

Wind farm data collected is given in Table 1; 10 min data is used in this paper, the data from 2010/07/02 00:10:00 A. to 2010/07/20 02:20:00 AM. $v(t-1)$ is wind speed data of previous sampling time period, and $P_{a}(t-1)$ is wind generator data of previous sampling time.

According to the literature [1], the relationship between wind energy utilization coefficient and tip speed ratio can be known. As in Figure 2, the tip speed ratio reaches optimum value, the maximum wind energy utilization coefficient $C_{p \max }$ is around 0.47 , tip speed ratio optimum value is around 7 , and blade pitch angle is around 0 degree; 
TABLE 1: 10 min sample data of SCADA system.

\begin{tabular}{lccccc}
\hline $\begin{array}{l}\text { Sampling } \\
\text { points }\end{array}$ & $\begin{array}{c}v(t-1) \\
(\mathrm{m} / \mathrm{s})\end{array}$ & $\begin{array}{c}v(t) \\
(\mathrm{m} / \mathrm{s})\end{array}$ & $\ldots$ & $\begin{array}{c}p_{a}(t-1) \\
(\mathrm{Kw})\end{array}$ & $\begin{array}{c}p_{a}(t) \\
(\mathrm{Kw})\end{array}$ \\
\hline 1 & 2 & 3 & $\ldots$ & 0 & 0 \\
$\vdots$ & $\vdots$ & $\vdots$ & $\ldots$ & $\vdots$ & $\vdots$ \\
300 & 11 & 12 & $\ldots$ & 793 & 801 \\
\hline
\end{tabular}

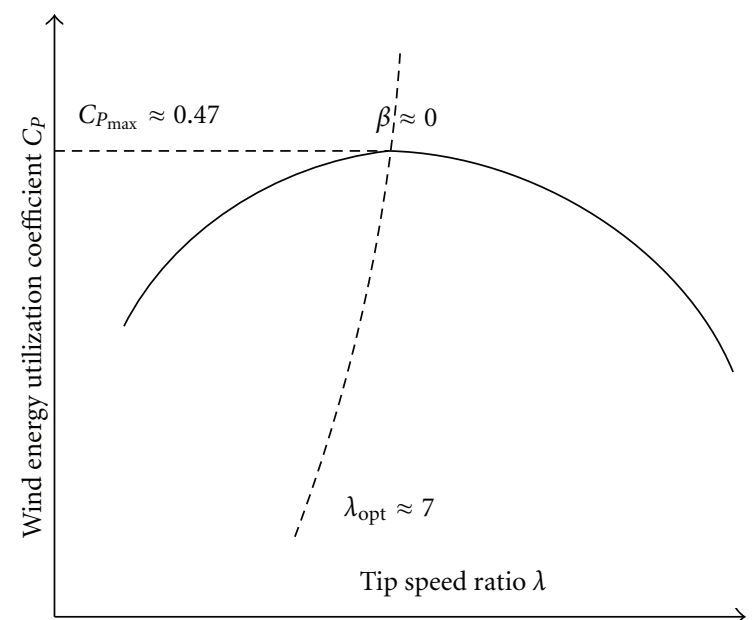

FIGURE 2: Wind energy utilization coefficient versus tip speed ratio.

the figure has general applicability to the variable speed constant frequency wind turbine:

$$
\begin{gathered}
\Gamma(t)=C v(t)^{2} C_{\Gamma}(\lambda), \\
\Omega_{w}(t)=\frac{P_{w}(t)}{\Gamma(t)}, \\
P_{w}(t)=\frac{C}{R} v(t)^{3} C_{P}(\lambda) .
\end{gathered}
$$

Letting, $C=0.5 \pi \rho R^{3}$, in (1), $\Gamma$ is wind wheel torque, $\rho$ is air density, $R$ is radius of the wind wheel, and $v$ is wind speed. The relationship between wind speed and wind turbine power output is shown in Figure $3, C_{\Gamma}(\lambda)$ is torque coefficient, $\lambda$ is tip speed ratio, $\lambda=\Omega_{W} R / v, \Omega_{W}$ is rotor speed, and $C_{p}(\lambda)$ is wind energy utilization coefficient. The relationship between $C_{\Gamma}(\lambda)$ and $C_{p}(\lambda)$ can be expressed as $C_{\Gamma}(\lambda)=\left(C_{p}(\lambda)\right) / \lambda$.

There are multiple unknown parameters and uncertainties in the WECS, the system has strong nonlinear characteristics, and its model is difficult to be established. Using the equivalent model and ignoring a number of uncertainties are often the solutions; however, the modeling accuracy is greatly reduced and seriously affects the control effect. Data-driven control only needs system input and output data. So, data-driven control model for the wind power system can be expressed as

$$
y_{j}=f_{j}\left[Q_{j}, R_{j}, u_{j}, x_{j},\left\{M_{i j}\right\}\right], \quad j=1,2,3, i=1,2 \ldots N,
$$

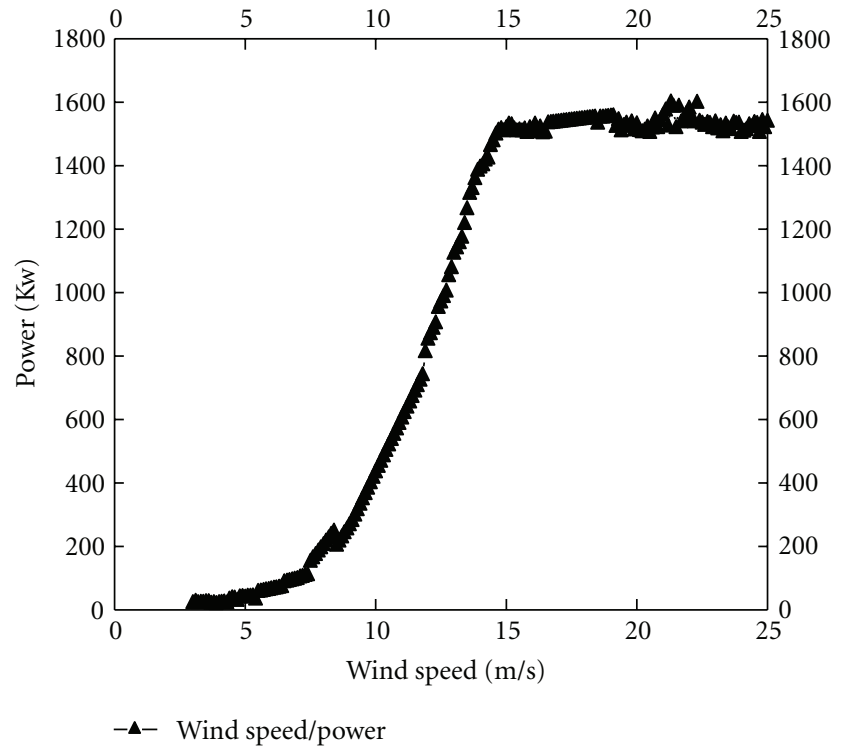

FIGURE 3: Wind speed versus wind generator power.

where $y_{j}$ is wind generator power output. Because three groups of data are selected for the experiment, $j=3, j$ can be selected as a different value according to actual needs. $x_{j}$ is system state, including wind generator speed, wind generator torque, and wind speed. $u_{j}$ is the system control input. $Q_{j}$ and $R_{j}$ are positive semidefinite symmetric weight matrices, $M_{i j}=\mathbf{C}_{j} \mathbf{A}_{j}^{(i-1)} \mathbf{B}_{j}$, where $M_{i j}$ are wind power control system Markov parameters:

$$
J=\varepsilon\left\{y_{j}^{T} Q_{j} y_{j}+\sum_{k=0}^{N-1}\left(y_{j}^{T} Q_{j} y_{j}+u_{j}^{T} R_{j} u_{j}\right)\right\} .
$$

\section{Data-Driven Control Methodology}

Lemma 1 (see [39]). The closed solution of differential Riccati equation is

$$
\begin{aligned}
\mathbf{X}(k)= & \mathbf{C}(k)^{T} \mathbf{Q}(k) \mathbf{C}(k)-\mathbf{C}(k)^{T} \mathbf{Q}(k) \mathbf{S}(k) \\
& \cdot\left(\mathbf{R}(k)+\mathbf{S}(k)^{T} \mathbf{Q}(k) \mathbf{S}(k)\right)^{-1} \mathbf{S}(k)^{T} \mathbf{Q}(k) \mathbf{C}(k),
\end{aligned}
$$

where

$$
\mathbf{C}(k)=\left[\begin{array}{c}
\mathbf{C} \\
\mathbf{C A} \\
\mathbf{C A}^{2} \\
\vdots \\
\mathbf{C A}^{N-k}
\end{array}\right],
$$

$$
\mathbf{S}(k)=\left[\begin{array}{ccccc}
\mathbf{0} & \cdots & \cdots & \cdots & \mathbf{0} \\
\mathbf{C B} & \mathbf{0} & \ddots & & \vdots \\
\mathbf{C A B} & \mathbf{C B} & \ddots & \ddots & \vdots \\
\vdots & \vdots & \ddots & \ddots & \vdots \\
\mathbf{C A}^{N-k-1} \mathbf{B}^{N-k-2} \mathbf{C} & \cdots & \mathbf{C B} & \mathbf{0}
\end{array}\right]
$$


$\mathbf{S}(N)=\mathbf{0}, \mathbf{R}(k)=\operatorname{diag}(\mathbf{R}, \mathbf{R}, \ldots, \mathbf{R})$ is block diagonal matrix with dimensions $(N-k+1) \cdot m$ and $\mathbf{Q}(k)=\operatorname{diag}(\mathbf{Q}, \mathbf{Q}, \ldots, \mathbf{Q})$ is block diagonal matrix with dimensions $(N-k+1) \cdot l$.

Theorem 2. For given Markov parameters of the WECS, after introduction of a closed solution of the differential Riccati equation, the data-driven controller can be expressed as

$$
U(k)=\mathbf{G}(k) \mathbf{x}_{c}(k), \quad j=1,2,3,
$$

where $\mathbf{G}(k)$ is the data-driven controller gain $\mathbf{x}_{c}(k)$ is the datadriven controller state

$$
\begin{aligned}
& \mathbf{G}(k)=-\left(R+\boldsymbol{\theta}(k+1)^{T} \boldsymbol{\Omega}(k+1) \boldsymbol{\theta}(k+1)\right)^{-1} \\
& \times \boldsymbol{\theta}(k+1)^{T} \boldsymbol{\Omega}(k+1), \\
& \mathbf{x}_{c}(k)=\mathbf{C}(k+1) \mathbf{A x}(k)=\left[\begin{array}{c}
\mathbf{C A} \\
\mathbf{C A}^{2} \\
\vdots \\
\mathbf{C A}^{N-k}
\end{array}\right] \mathbf{x}(k),
\end{aligned}
$$

where

$$
\begin{aligned}
\boldsymbol{\theta}(k+1)= & \mathbf{C}(k+1) \mathbf{B}=\left[\begin{array}{llll}
\mathbf{M}_{\mathbf{1}} & \mathbf{M}_{2} & \cdots & \mathbf{M}_{N-k}
\end{array}\right]^{T}, \\
\mathbf{\Omega}(k+1)= & \mathbf{Q}(k+1)-\mathbf{Q}(k+1) \mathbf{S}(k+1) \\
& \times\left(\mathbf{R}(k+1)+\mathbf{S}(k+1)^{T} \mathbf{Q}(k+1) \mathbf{S}(k+1)\right)^{-1} \\
& \times \mathbf{S}(k+1)^{T} \mathbf{Q}(k+1), \\
\mathbf{S}(k+1)= & {\left[\begin{array}{ccccc}
\mathbf{0} & \cdots & \cdots & \cdots & \mathbf{0} \\
\mathbf{M}_{\mathbf{1}} & \mathbf{0} & \ddots & & \vdots \\
\mathbf{M}_{2} & \mathbf{M}_{\mathbf{1}} & \ddots & \ddots & \vdots \\
\vdots & \vdots & \ddots & \ddots & \vdots \\
\mathbf{M}_{N-k-1} & \mathbf{M}_{N-k-2} & \cdots & \mathbf{M}_{\mathbf{1}} & \mathbf{0}
\end{array}\right](\mathbf{S}(N)=\mathbf{0}), }
\end{aligned}
$$

where $\mathbf{R}(k+1)=\operatorname{diag}(\mathbf{R}, \mathbf{R}, \ldots, \mathbf{R})$ is block diagonal matrix with dimensions $m(N-k)$ and $\mathbf{Q}(k+1)=\operatorname{diag}(\mathbf{Q}, \mathbf{Q}, \ldots, \mathbf{Q})$ is block diagonal matrix with dimensions $l(N-k) . \mathbf{A}_{j}, \mathbf{B}_{j}$, and $\mathbf{C}_{j}$ of the Markov parameters $M_{i j}$ can be obtained by the input $u_{j}$ and output $y_{j}$, and the column vectors $\mathbf{u}_{j}(k)$ and $\mathbf{y}_{j}(k)$ are formed by $p$-Step input and output data from the beginning of the $\left\{u_{j}, y_{j}\right\}$ :

$$
\begin{aligned}
& U_{j}(k)=\left[\begin{array}{lll}
\mathbf{u}_{j 1}(k) & \cdots & \mathbf{u}_{j p-1}(k+p-1)
\end{array}\right]^{T}, \quad j=1,2,3, \\
& Y_{j}(k)=\left[\begin{array}{lll}
y_{j 1}(k) & \cdots & y_{j p-1}(k+p-1)
\end{array}\right]^{T}, \quad j=1,2,3 .
\end{aligned}
$$

Then, matrices $\mathbf{Y}_{j}$ and $\mathbf{V}_{j}$ in (11) can be formed by the input data and output data. The relationship between input and output data can be expressed as (12)

$$
\begin{gathered}
\mathbf{Y}_{j}=\left[\begin{array}{lll}
\mathbf{y}_{j 1}(k+p) & \cdots & \mathbf{y}_{j L}(k+p+L)
\end{array}\right], \quad j=1,2,3, \\
\mathbf{V}_{j}=\left[\begin{array}{ccc}
\mathbf{u}_{j}(k) & \cdots & \mathbf{u}_{j}(k+L) \\
\mathbf{u}_{j p}(k+p) & \cdots & \mathbf{u}_{j p}(k+p+L) \\
\mathbf{y}_{j}(k) & \cdots & \mathbf{y}_{j L}(k+L)
\end{array}\right], \quad j=1,2,3,
\end{gathered}
$$

$$
\left[\begin{array}{lll}
\mathbf{P}_{j 1} & \mathbf{T}_{j p} & \mathbf{P}_{j 2}
\end{array}\right]=\mathbf{Y}_{j} \mathbf{V}_{j}^{T}\left(\mathbf{V}_{j} \mathbf{V}_{j}^{T}\right)^{+}, \quad j=1,2,3,
$$

where

$$
\begin{gathered}
\mathbf{P}_{j 1}=\mathbf{O}_{j p}\left(\mathbf{B}_{j p}+\mathbf{M}_{j} \mathbf{T}_{j p}\right), \\
\mathbf{P}_{j 2}=-\mathbf{O}_{j p} \mathbf{M}_{j}, \mathbf{M}_{j}=-A_{j}^{p} \mathbf{O}_{j p}^{+}, \\
\mathbf{B}_{j p}=\left[\begin{array}{llll}
\mathbf{A}_{j}^{p-1} \mathbf{B}_{j} & \cdots & \mathbf{A}_{j} \mathbf{B}_{j} & \mathbf{B}_{j}
\end{array}\right], \\
\mathbf{O}_{j p}=\left[\begin{array}{c}
\mathbf{C}_{j} \\
\mathbf{C}_{j} \mathbf{A}_{j} \\
\vdots \\
\mathbf{C}_{j} \mathbf{A}_{j}^{p-1}
\end{array}\right] j=1,2,3,
\end{gathered}
$$

$$
\mathbf{T}_{j p}=\left[\begin{array}{ccccc}
0 & \cdots & \cdots & \cdots & 0 \\
\mathbf{C}_{j} \mathbf{B}_{j} & 0 & \ddots & & \vdots \\
\mathbf{C}_{j} \mathbf{A}_{j} \mathbf{B}_{j} & \mathbf{C}_{j} \mathbf{B}_{j} & \ddots & \ddots & \vdots \\
\vdots & \vdots & \ddots & \ddots & \vdots \\
\mathbf{C}_{j} \mathbf{A}_{j}{ }^{p-2} \mathbf{B}_{j} & \mathbf{C}_{j} \mathbf{A}_{j}{ }^{p-3} \mathbf{B}_{j} & \cdots & \mathbf{C}_{j} \mathbf{B}_{j} & 0
\end{array}\right] \quad j=1,2,3 .
$$

$\mathbf{P}_{j 1}, \mathbf{P}_{j 2}$, and matrix $\mathbf{T}_{j p}$ can be obtained by solving (9); when $p=N+1$, the WECS Markov parameters $M_{i j}$ can be extracted from $\mathbf{T}_{j p}$.

The test time is from 2010/07/21 00:30:10 AM to 2010/ 07/29 00:25:30 AM, corresponding control input data and output data set are $\left\{u_{1}, y_{1}\right\},\left\{u_{2}, y_{2}\right\},\left\{u_{3}, y_{3}\right\}$ and The original power output and the optimized power output are shown by Figures 4(a)-4(c). It can be seen that data-driven controller can effectively identify wind turbine power output and control precision achieves the desired effect.

\section{Neural Network Optimization}

As shown in Figure 2, the tip speed ratio can be adjusted by controlling wind generator speed to improve wind energy utilization coefficient $C_{p}$. Wind generator speed is optimized by neural network compensator to improve wind energy capture efficiency. Neural network performance evaluation [40-43] is expressed as (14)

$$
J=\min E\left(\int_{t=0}^{\infty}\left(O_{t i}-O_{i}\right)^{2} \mathrm{~d} t\right)
$$

where $O_{t i}$ is the target output of the compensator and $i=$ $1,2, \ldots, n . O_{i}$ is the actual output of the compensator, which 


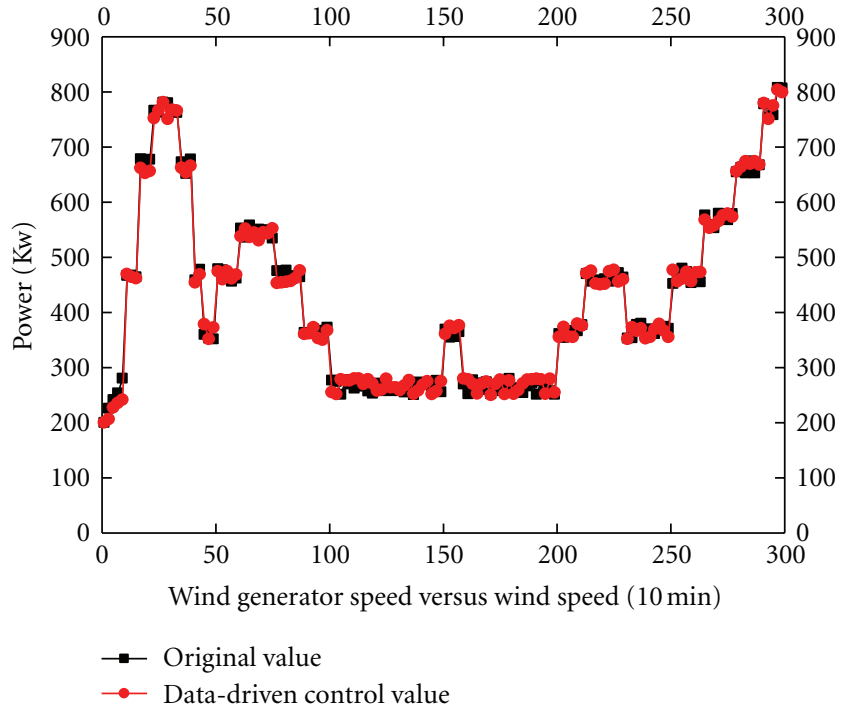

(a) Wind speed versus wind generator speed

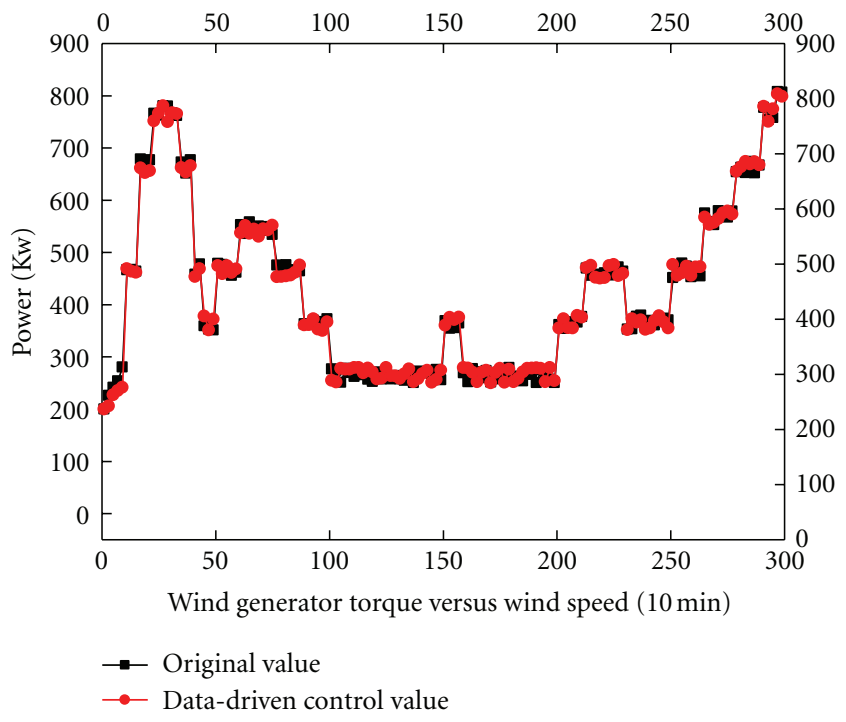

(b) Wind generator torque versus wind speed



(c) Wind generator torque versus wind generator speed

Figure 4: Power output.

is $\Delta u_{j n n}(k)$ in (17). Neural networks have many learning rules; different learning rules lead to different training efficiency, OUTSTAR learning rules are used to train neural network compensator in this paper, which is intended to generate an $m$-dimensional desired output vector. Weight vector $\Delta W_{k}$ of OUTSTAR learning rule can be expressed as

$$
\Delta W_{k}=\eta\left(d-W_{k}\right) .
$$

Before adding the data-driven controller, open-loop input data which constitutes the matrix $\mathbf{Y}_{j}$ and output data which constitutes the matrix $\mathbf{V}_{j}$ are collected, row vector of matrix $\mathbf{V}_{j}$ and matrix $\mathbf{Y}_{j}$ must be linearly independent. Inputs of the neural network compensator are $e_{j}(k-1)$, $y_{j}(k-1)$, and $\Delta u_{j}(k) ; \Delta u_{j}(k)$ is the error between datadriven controller current input $u\left(k, x_{j}\right)$ and previous input $u\left(k-1, x_{j}\right)$. Output of the compensator is $\Delta u_{j n n}(k) ; \Delta u_{j n n}(k)$ is the error between neural network current input $u_{j n n}\left(k, x_{j}\right)$ and previous input $u_{j n n}\left(k-1, x_{j}\right)$ :

$$
\begin{gathered}
\Delta u_{j}(k)=u\left(k, x_{j}\right)-u\left(k-1, x_{j}\right), \\
\Delta u_{j n n}(k)=u_{j n n}\left(k, x_{j}\right)-u_{j n n}\left(k-1, x_{j}\right) .
\end{gathered}
$$

The method has general applicability, so randomly wind turbine 1, wind turbine 2, and wind turbine 3 are selected as the study objects, and learning rules of EBPA and LMS are used to train the neural network compensator also. Equation (18) give the wind turbine output power mean absolute error (MAE), the standard deviation of mean absolute error (SD of MAE), the relative mean absolute error (RMAE), and 


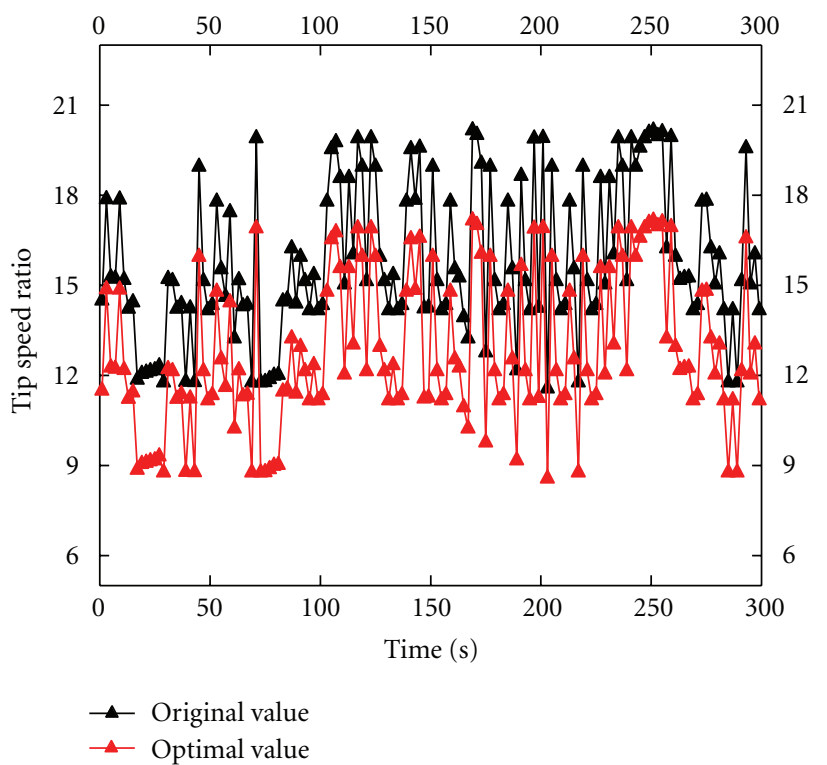

(a) Tip speed ratio

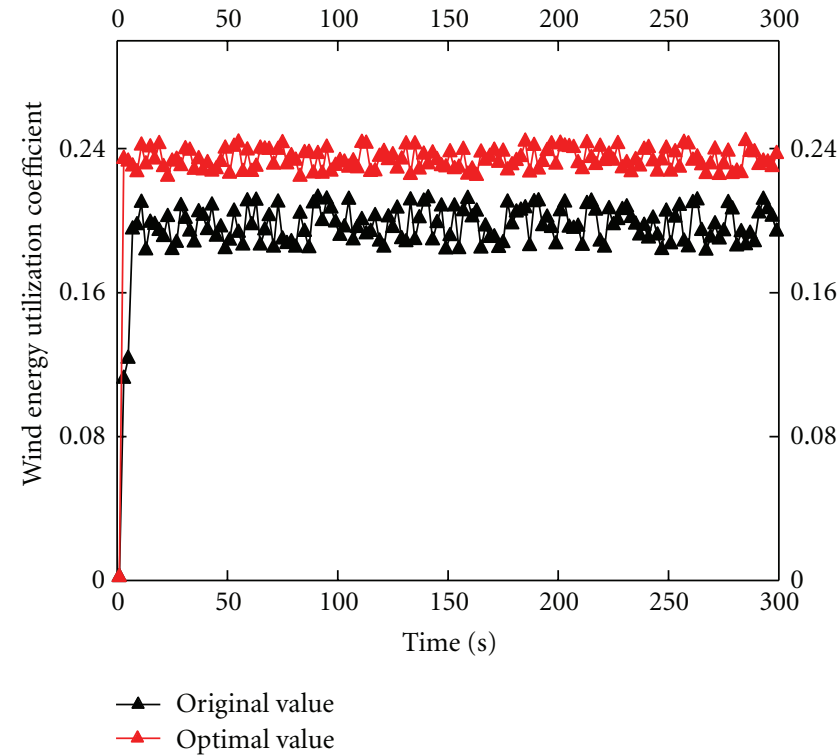

(b) Wind energy utilization coefficient

FIGURE 5: Wind energy utilization coefficient versus tip speed ratio.

the standard deviation of relative mean absolute error (SD of RMAE), where $y_{K}$ is control output, $y_{0}$ is instance value, and $n$ is sample number. It can be seen that the model built on the collected data is stabler with the OUTSTAR learning rules. Output error with different training rules is given in Table 2:

$$
\begin{aligned}
\text { MAE } & =\frac{\sum_{K=1}^{n}\left|y_{K}-y_{0}\right|}{n}, \\
\text { STD of MAE } & =\sqrt{\frac{\sum_{K=1}^{n}\left(y_{K}-y_{0}\right)^{2}}{n}}, \\
\text { RMAE } & =\frac{\sum_{K=1}^{n}\left|y_{K}-y_{0}\right|}{n y_{0}}, \\
\text { STD of RMAE } & =\sqrt{\frac{\sum_{K=1}^{n}\left(\left(y_{K}-y_{0}\right) / y_{0}\right)^{2}}{n}} .
\end{aligned}
$$

\section{Analysis and Results}

The original value and optimal value of wind energy utilization coefficient are compared in Figure 5, it can be known wind energy captured is increasing by adjusting tip speed ratio value, as the tip speed ratio is close to the optimal value, the value of wind energy utilization coefficient is increasing. Wind turbine 1 is taken as study object, and a 5-17-1 neural network is selected to optimize wind energy captured by the wind wheel. Figure 6(a) gives the original and optimal generator speeds. It can be seen that the optimal generator speed is stabler than the original one. Figure 6(b) gives the original and optimal power output. It can be seen that the optimal power is more than the original one.
TABLE 2: Output error with different training rules.

\begin{tabular}{lcccc}
\hline Learning rules & MAE $(\mathrm{Kw})$ & STD of MAE & RMAE STD of RMAE \\
\hline $\begin{array}{l}\text { Turbine } 1 \\
\quad\end{array}$ & & & & \\
EBPA & 4.30 & 2.01 & 0.12 & 0.02 \\
LMS & 3.30 & 1.23 & 0.08 & 0.02 \\
$\quad$ OUTSTAR & 2.25 & 0.95 & 0.05 & 0.01 \\
\hline Turbine 2 & & & & \\
EBPA & 4.32 & 2.05 & 0.15 & 0.03 \\
LMS & 3.27 & 1.22 & 0.07 & 0.03 \\
OUTSTAR & 2.33 & 0.93 & 0.06 & 0.02 \\
\hline Turbine 3 & & & & \\
$\quad$ EBPA & 4.28 & 1.98 & 0.10 & 0.02 \\
LMS & 3.21 & 1.03 & 0.08 & 0.01 \\
OUTSTAR & 2.15 & 0.86 & 0.05 & 0.01 \\
\hline
\end{tabular}

\section{Conclusion}

In this paper, data-driven controller for the WECS is designed based on neural network, Markov parameters of the data-driven controller can be obtained by input and output data of the WECS. To overcome the inadequacy of data-driven control, neural network compensator is used to compensate for the deviation output of wind power datadriven control system; the results show that the system stable performance is improved.

10 min data of wind farm SCADA system is collected, including wind generator power output, wind generator speed, wind energy utilization coefficient, and tip speed ratio. The method first determines the WECS Markov parameters, the system output is controlled by adjusting the data-driven controller gain, and the neural network is trained by different 


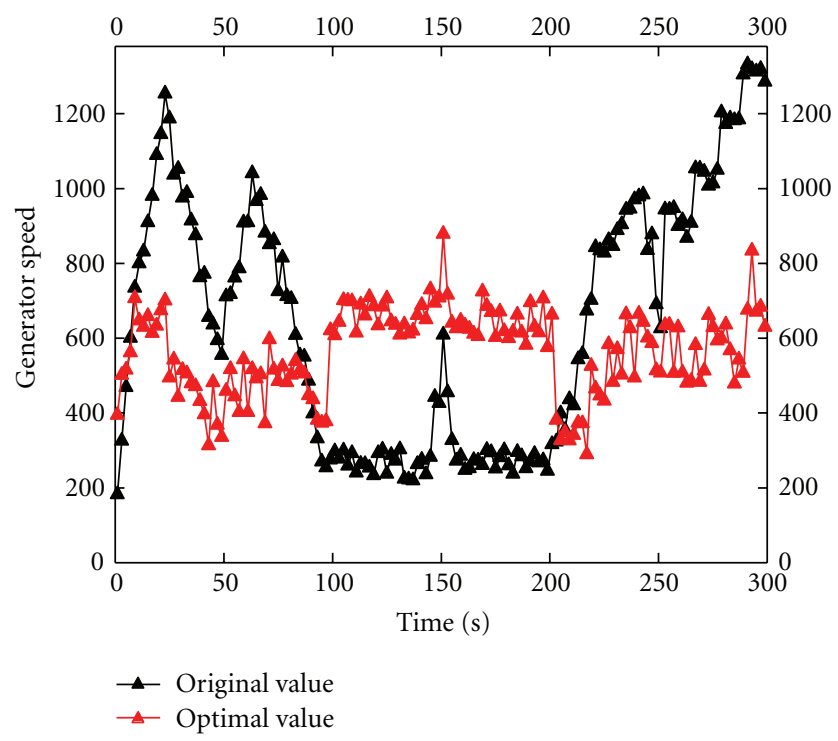

(a) Power output

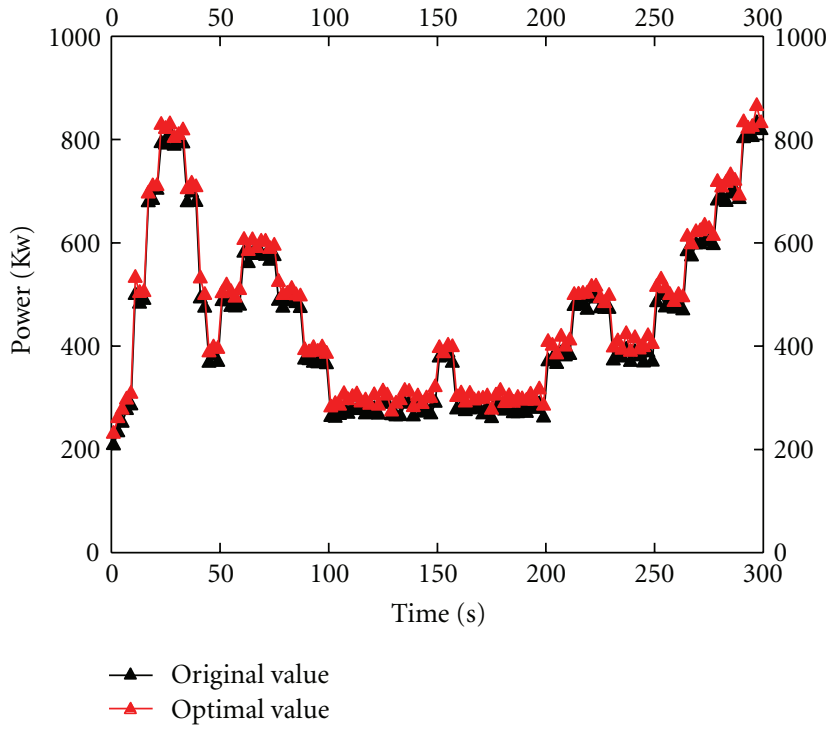

(b) Generator speed

Figure 6: Optimized output.

neural network learning rules. The results show that the generator speed fluctuations can be reduced, the security of wind turbine operation is high, more wind energy is captured, and the method is relatively simple and easy to understand.

\section{References}

[1] W. M. Lin and C. M. Hong, "Intelligent approach to maximum power point tracking control strategy for variable-speed wind turbine generation system," Energy, vol. 35, no. 6, pp. 2440 2447, 2010.

[2] C. Y. Lee, P. H. Chen, and Y. X. Shen, "Maximum power point tracking (MPPT) system of small wind power generator using RBFNN approach," Expert Systems with Applications, vol. 38, no. 10, pp. 12058-12065, 2011.

[3] H. Camblong, I. M. de Alegria, M. Rodriguez, and G. Abad, "Experimental evaluation of wind turbines maximum power point tracking controllers," Energy Conversion and Management, vol. 47, no. 18-19, pp. 2846-2858, 2006.

[4] E. A. Bossanyi, "The design of closed loop controllers for wind turbines," Wind Energy, vol. 3, no. 3, pp. 149-163, 2000.

[5] E. Muljadi, K. Pierce, and P. Migliore, "A conservative control strategy for variable-speed stall regulated wind turbines," Tech. Rep. NREL/CP-500-24791, National Renewable Energy Laboratory, Golden, Colo, USA, 2000.

[6] I. Munteanu, N. A. Cutululis, A. I. Bratcu, and E. Ceangă, "Optimization of variable speed wind power systems based on a LQG approach," Control Engineering Practice, vol. 13, no. 7, pp. 903-912, 2005.

[7] E. B. Muhando, T. Senjyu, H. Kinjo, and T. Funabashi, "Augmented LQG controller for enhancement of online dynamic performance for WTG system," Renewable Energy, vol. 33, no. 8, pp. 1942-1952, 2008.

[8] V. Calderaro, V. Galdi, A. Piccolo, and P. Siano, "A fuzzy controller for maximum energy extraction from variable speed wind power generation systems," Electric Power Systems Research, vol. 78, no. 6, pp. 1109-1118, 2008.

[9] X. M. Tian, G. Chen, and S. Chen, "A data-based approach for multivariate model predictive control performance monitoring," Neurocomputing, vol. 74, no. 4, pp. 588-597, 2011.

[10] J. van Helvoort, B. de Jager, and M. Steinbuch, "Direct data-driven recursive controller unfalsification with analytic update," Automatica, vol. 43, no. 12, pp. 2034-2046, 2007.

[11] G. O. Guardabassi and S. M. Savaresi, "Virtual reference direct design method: an off-line approach to data-based control system design," IEEE Transactions on Automatic Control, vol. 45, no. 5, pp. 954-959, 2000.

[12] Z. S. Hou and W. H. Huang, "The model-free learning adaptive control of a class of SISO nonlinear systems," in Proceedings of the American Control Conference, pp. 343-344, Albuquerque, NM, USA, June 1997.

[13] J. C. Spall and J. A. Cristion, "Model-free control of nonlinear stochastic systems with discrete-time measurements," IEEE Transactions on Automatic Control, vol. 43, no. 9, pp. 11981210, 1998.

[14] Z.-S. Hou and J.-W. Yan, "Model free adaptive control based freeway ramp metering with feed forward iterative learning controller," Acta Automatica Sinica, vol. 35, no. 5, pp. 588-595, 2009.

[15] C. S. Byington, M. Watson, and D. Edwards, "Data-driven neural network methodology to remaining life predictions for aircraft actuator components," in Proceedings of the IEEE Aerospace Conference Proceedings, pp. 3581-3589, New York, NY, USA, March 2004.

[16] J.-X. Xu and Z.-S. Hou, "Notes on data-driven system approaches," Acta Automatica Sinica, vol. 35, no. 6, pp. 668$675,2009$.

[17] C. M. Lee and S. Narayanan, "Emotion recognition using a data-driven fuzzy inference system," in Proceedings of the European Conference on Speech Communication and Technology, pp. 157-160, 2003. 
[18] M. Al-Khatib and J. J. Saade, "An efficient data-driven fuzzy approach to the motion planning problem of a mobile robot," Fuzzy Sets and Systems, vol. 134, no. 1, pp. 65-82, 2003.

[19] A. Khoukhi, "Data-driven multi-stage motion planning of parallel kinematic machines," IEEE Transactions on Control Systems Technology, vol. 18, no. 6, pp. 1381-1389, 2010.

[20] Z. Hou and S. Jin, "A novel data-driven control approach for a class of discrete-time nonlinear systems," IEEE Transactions on Control Systems Technology, vol. 19, no. 6, pp. 1549-1558, 2011.

[21] Z. Hou and X. Bu, "Model free adaptive control with data dropouts," Expert Systems with Applications, vol. 38, no. 8, pp. 10709-10717, 2011.

[22] L. D. S. Coelho, M. W. Pessôa, R. R. Sumar, and A. A. R. Coelho, "Model-free adaptive control design using evolutionary-neural compensator," Expert Systems with Applications, vol. 37, no. 1, pp. 499-508, 2010.

[23] K. Yamuna Rani, "Sensitivity compensating control: datadriven model based adaptive approach," Journal of Process Control, vol. 21, no. 9, pp. 1265-1286, 2011.

[24] K. Methaprayoon, C. Y. Vivatana Pong, W.-J. Lee, and J. R. Liao, "An integration of ANN wind power estimation into unit commitment considering the forecasting uncertainty," IEEE Transactions on Industry Applications, vol. 43, no. 6, pp. 14411448, 2007.

[25] M. C. Alexiadis, P. S. Dokopoulos, and H. S. Sahsamanoglou, "Wind speed and power forecasting based on spatial correlation models," IEEE Transactions on Energy Conversion, vol. 14, no. 3, pp. 836-842, 1999.

[26] J. Sargolzaei and A. Kianifar, "Modeling and simulation of wind turbine Savonius rotors using artificial neural networks for estimation of the power ratio and torque," Simulation Modelling Practice and Theory, vol. 17, no. 7, pp. 1290-1298, 2009.

[27] A. S. Yilmaz and Z. Özer, "Pitch angle control in wind turbines above the rated wind speed by multi-layer perceptron and radial basis function neural networks," Expert Systems with Applications, vol. 36, no. 6, pp. 9767-9775, 2009.

[28] M. Bayat, M. Sedighizadeh, and A. Rezazadeh, "Wind energy conversion systems control using inverse neural model algorithm," International Journal of Engineering and Applied Sciences, vol. 2, no. 3, pp. 40-46, 2010.

[29] A. Kusiak and H. Zheng, "Optimization of wind turbine energy and power factor with an evolutionary computation algorithm," Energy, vol. 35, no. 3, pp. 1324-1332, 2010.

[30] A. Kusiak, H. Zheng, and Z. Song, "Power optimization of wind turbines with data mining and evolutionary computation," Renewable Energy, vol. 35, no. 3, pp. 695-702, 2010.

[31] S. Yang and V. Ajjarapu, "A speed-adaptive reduced-order observer for sensorless vector control of doubly fed induction generator-based variable-speed wind turbines," IEEE Transactions on Energy Conversion, vol. 25, no. 3, pp. 891-900, 2010.

[32] J. J. Rubio, M. Figueroa, J. Pacheco, and M. Jimenes-Lizarraga, "Observer design based in the mathematical model of a wind turbine," InternationalJournal of Innovative Computing, Information and Control, vol. 7, no. 12, pp. 6711-6725, 2011.

[33] J. J. Rubio, P. Angelov, and J. Pacheco, "Uniformly stable backpropagation algorithm to train a feedforward neural network," IEEE Transactions on Neural Networks, vol. 22, no. 3, pp. 356-366, 2011.

[34] X. Ren and X. Lv, "Identification of extended Hammerstein systems using dynamic self-optimizing neural networks," IEEE Transactions on Neural Networks, vol. 22, no. 8, pp. 1169-1179, 2011.
[35] C. K. Ahn, "Takagi-Sugeno fuzzy hopfield neural networks for $\mathrm{H}_{\infty}$ nonlinear system identification," Neural Processing Letters, vol. 34, no. 1, pp. 59-70, 2011.

[36] J. J. Rubio, F. Ortiz, C. R. Mariaca, and J. C. Tovar, "A method for online pattern recognition of abnormal eye movements," Neural Computing and Applications. In press.

[37] A. Kusiak, Z. Zhang, and M. Y. Li, "Optimization of wind turbine performance with data-driven models," IEEE Transactions on Sustainable Energy, vol. 1, no. 2, pp. 66-76, 2010.

[38] A. Kusiak and Z. Zhang, "Adaptive control of a wind turbine with data mining and swarm intelligence," IEEE Transactions on Sustainable Energy, vol. 2, no. 1, pp. 28-36, 2011.

[39] K. Furuta and M. Wongsaisuwan, "A generalized inversed inverse solution to the discrete-time singular riccati equation," IEEE Transactions on Automatic Control, vol. 26, no. 2, pp. 395-398, 1981.

[40] J. J. Rubio, P. Angelov, and J. Pacheco, "Uniformly stable backpropagation algorithm to train a feedforward neural network," IEEE Transactions on Neural Networks, vol. 22, no. 3, pp. 356$366,2011$.

[41] X. Ren and X. Lv, "Identification of extended Hammerstein systems using dynamic self-optimizing neural networks," IEEE Transactions on Neural Networks, vol. 22, no. 8, pp. 1169-1179, 2011.

[42] C. K. Ahn, "Takagi-Sugeno fuzzy hopfield neural networks for $\mathrm{H}_{\infty}$ nonlinear system identification," Neural Processing Letters, vol. 34, no. 1, pp. 59-70, 2011.

[43] J. J. Rubio, F. Ortiz, C. R. Mariaca, and J. C. Tovar, "Amethod for online pattern recognition of abnormal eye movements," Neural Computing and Applications. In press. 

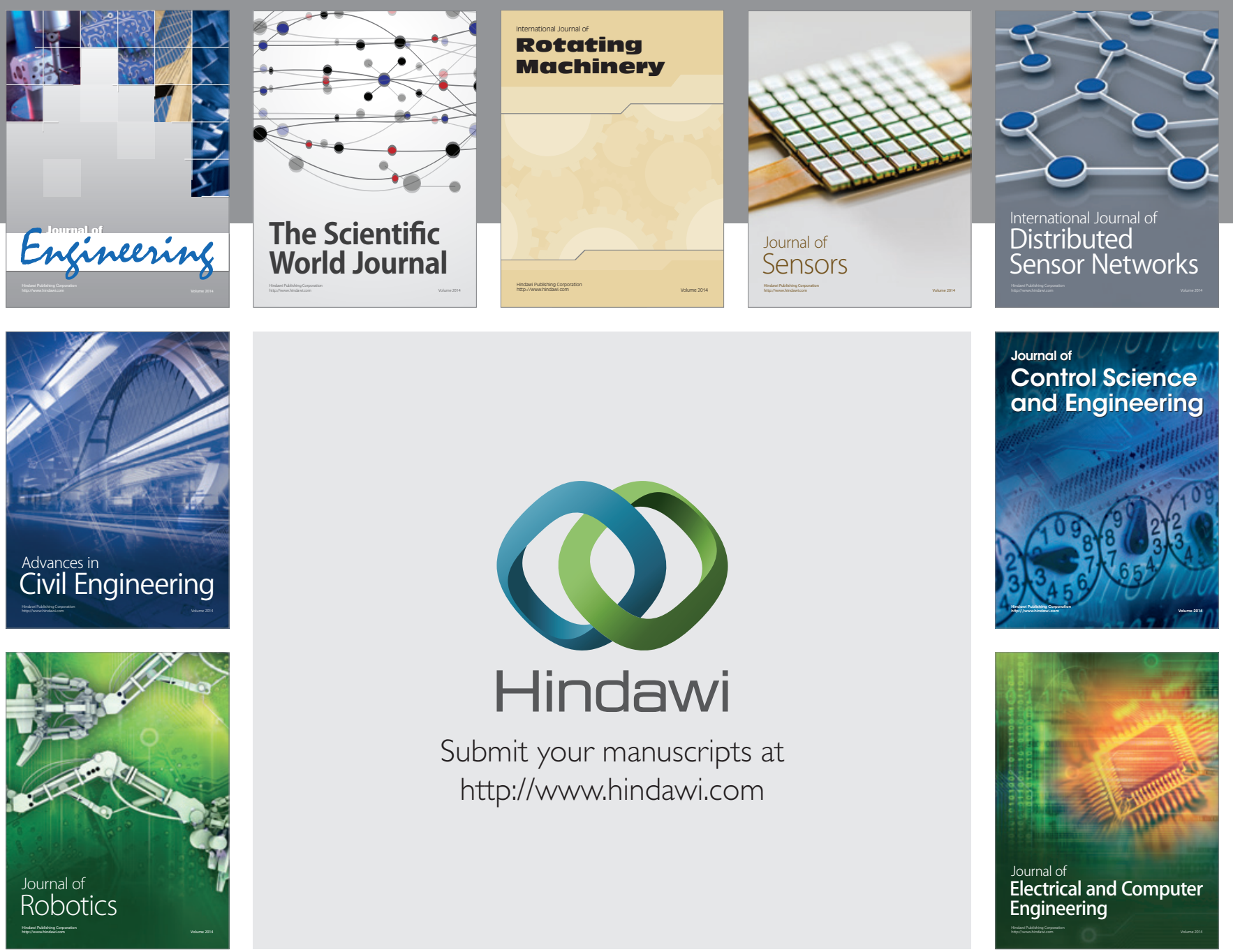

Submit your manuscripts at

http://www.hindawi.com
